(C) 2022, The Authors. Published by Elsevier Inc. and Fass Inc. on behalf of the American Dairy Science Association ${ }^{\circledR}$. This is an open access article under the CC BY license (http://creativecommons.org/licenses/by/4.0/).

\title{
Effect of pegbovigrastim on fertility and culling in grazing dairy cows and its association with prepartum nonesterified fatty acids
}

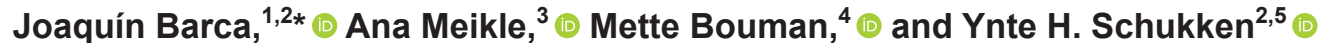 \\ ${ }^{1}$ Department of Dairy Science and Technology, Veterinary Faculty, Universidad de la República, Montevideo, 11600, Uruguay \\ ${ }^{2}$ Department of Animal Sciences, Wageningen University, Wageningen, $6700 \mathrm{AH}$, the Netherlands \\ ${ }^{3}$ Animal Endocrine and Metabolism Laboratory, Veterinary Faculty, Universidad de la República, Montevideo, 11600, Uruguay \\ ${ }^{4}$ Veterinary Practitioner, Colonia, 70400 , Uruguay \\ ${ }^{5}$ Royal GD, Deventer, 7400 AA, the Netherlands
}

\begin{abstract}
This randomized controlled trial on 4 commercial grazing dairy farms investigated whether treatment with pegbovigrastim (PEG) affected fertility and culling as measured during the full lactation. We also explored the effect of potential interactions of PEG treatment with parity, prepartum body condition score, prepartum nonesterified fatty acid concentration (pre-NEFA), and early-lactation clinical disease on these outcomes. Holstein cows were randomly assigned to 1 of 2 trial arms: a first PEG dose approximately $7 \mathrm{~d}$ before the expected calving date and a second dose within $24 \mathrm{~h}$ after calving (PEG: primiparous $=342 ;$ multiparous $=$ 697) compared with untreated controls (control: primiparous $=391$; multiparous $=723$ ). Cox's proportional hazards regression models were used to analyze rate of first insemination, rate of pregnancy [within 150 and $305 \mathrm{~d}$ in milk (DIM)], and hazard of culling. Additional analyses were performed on data that were stratified by parity group and pre-NEFA class (low $\leq 0.3$; high $>0.3 \mathrm{mM}$ ). In high pre-NEFA cows, PEG treatment increased the rate of first insemination [hazard ratio $(\mathrm{HR})=1.15]$. Early-lactation clinical mastitis $(\mathrm{CM})$ and uterine disease (UD: retained placenta, metritis, or both) were associated with a reduced rate of pregnancy within 150 DIM (HR $=0.49$ and 0.78, respectively). Pegbovigrastim treatment in high pre-NEFA cows with $\mathrm{CM}$ and UD increased the rate of pregnancy within 150 DIM ( $\mathrm{HR}=1.75$ and 1.46, respectively). In high pre-NEFA cows, PEG treatment resulted in a lower hazard of culling $(\mathrm{HR}=0.79)$. No treatment effect was detected in low pre-NEFA cows. This study shows that the effect of PEG treatment on fertility and culling interacts with pre-NEFA. In high pre-NEFA cows,
\end{abstract}

Received May 25, 2021.

Accepted September 14, 2021.

*Corresponding author: barca.joaquin@gmail.com
PEG treatment increased the rate of first insemination, counteracted the negative association of early-lactation CM and UD with the rate of pregnancy, and decreased the hazard of culling.

Key words: pegbovigrastim, grazing transition cow, fertility, culling, nonesterified fatty acids

\section{INTRODUCTION}

The metabolic challenges that dairy cows experience around parturition (Grummer, 1995; Drackley, 1999) considerably impair their immune response (Trevisi and Minuti, 2018; Gross and Bruckmaier, 2019). Metabolites related to negative energy balance (NEB), such as nonesterified fatty acids (NEFA) and BHB, have been identified as immunosuppressants (Ingvartsen and Moyes, 2015). Elevated NEFA concentrations were associated with decreased white blood cell and neutrophil counts (Hachenberg et al., 2007; Barca et al., 2021a) and impaired neutrophil and lymphocyte function (Lacetera et al., 2005; LeBlanc, 2020). Moreover, epidemiological studies have shown that elevated NEFA concentrations are associated with increased risk of diseases such as mastitis, retained placenta (RP), and metritis (LeBlanc et al., 2004; Melendez et al., 2009; Galvão et al., 2010).

A recent meta-analysis (Dolecheck et al., 2019) suggested that time to first insemination and time to pregnancy in an animal with clinical mastitis (CM) before its first insemination is increased. Uterine diseases have been linked to impaired fertility, where RP, metritis, and endometritis delayed time to first insemination and time to pregnancy (Fourichon et al., 2000; LeBlanc et al., 2002; Toni et al., 2015). Both CM and poor fertility are also major reasons for culling (Kossaibati and Esslemont, 1997; Bar et al., 2008; Hertl et al., 2018).

The use of a long-acting analog of bovine granulocyte colony-stimulating factor (pegbovigrastim or PEG, marketed as Imrestor by Elanco Animal Health) has 
been reported to be beneficial, as treatment reduced the incidence of early-lactation CM (Canning et al., 2017; Ruiz et al., 2017; Barca et al., 2021b). However, Zinicola et al. (2018), including only cows with optimal body condition in late gestation, reported an absence of treatment effect on CM. More recently, Van Schyndel et al. (2021), including cows regardless of body condition, reported a lack of PEG treatment effect on the incidence of mastitis. Evidence for the use of PEG to improve uterine health has been inconsistent, since increases (Ruiz et al., 2017), decreases (Freick et al., 2018), or lack of effect (Zinicola et al., 2018; Van Schyndel et al., 2021) on metritis incidence were reported. We recently reported that treatment with PEG reduced the occurrence of endometritis in cows that had previous metritis (Barca et al., 2021b).

Treatment with PEG reduced failure to return to estrus within 80 DIM (Canning et al., 2017) and increased the rate of insemination by $5.8 \%$ during the first 100 DIM (Ruiz et al., 2017). In contrast, Zinicola et al. (2018) reported a lack of PEG treatment effect on rate of insemination during the first 120 DIM and rate of pregnancy during the first 180 DIM. Zinicola et al. (2018) also reported a lack of effect of PEG on the hazard of culling during the first 180 DIM. Van Schyndel et al. (2021) reported a lack of PEG treatment effect on the hazard of culling during the first 63 DIM, rate of first insemination during the first 150 DIM, and rate of pregnancy during the first 250 DIM. These studies were carried out under various management conditions, and to our knowledge, there are no reports on the effect of PEG treatment on fertility and culling under grazing conditions.

Recently, we showed that treatment with PEG prevented the negative association of prepartum NEFA concentration with postpartum neutrophil counts (Barca et al., 2021a). In addition, we found that PEG reduced the occurrence of a first case of $\mathrm{CM}$ during the first 30 DIM, particularly in cows with elevated prepartum NEFA concentrations and in cows with excessive prepartum BCS (Barca et al., 2021b).

As far as we know, there are no reports on the effect of PEG on fertility or culling as measured during a full lactation. This is of relevance as fertility and especially culling are particularly important later in lactation (Ribeiro et al., 2016; Carvalho et al., 2019). Hence, full lactation follow-up will provide a more complete picture of the effect of PEG treatment on fertility and herd life.

Therefore, we hypothesized that PEG would increase fertility and decrease culling, and that the relationship between PEG treatment and fertility and culling outcomes would interact with prepartum BCS, prepartum NEFA, or both. Thus, we investigated whether
PEG treatment affects fertility and culling during a full lactation in grazing dairy cows. We also explored the effect of PEG treatment interactions with parity, prepartum BCS, prepartum NEFA concentration, and early-lactation clinical disease on these outcomes.

\section{MATERIALS AND METHODS}

The experimental protocol (CEUAFVET-PI-162) was evaluated and approved by the Honorary Committee for Animal Experimentation in Uruguay, University of the Republic, Uruguay.

\section{Study Design}

This randomized controlled trial was conducted on 4 commercial grazing dairy farms in 3 different regions of Uruguay. A total of 2,336 Holstein primiparous (animals that were enrolled in the study shortly before their first calving) and multiparous cows (animals that were enrolled shortly before their second or higher calving) were assessed for enrollment on the 4 farms. Farms 1,3 , and 4 had a seasonal calving system, with calving concentrated in autumn. These herds had a milking herd size of approximately 1,000, 850, and 600 cows, respectively. Farm 2 had a continuous year-round calving system and a milking herd size of approximately 600 cows. All farms used AI with estrus detection performed by trained farm personnel. Pregnancy diagnoses were performed by transrectal palpation or ultrasonography by the farm veterinarian.

All cows from each farm were located in outdoor close-up paddocks around 3 wk before the expected calving date, where cows were fed a partial mixed ration (Supplemental Table S1, http://dx.doi.org/DOI:10 .17632/ftkm7775kn.3, Barca, 2021) twice a day. Calving was in the same area or in a subdivision of the same paddock under the same conditions. Calving of cows included in the study occurred from February 13 to September 30, 2018. After calving, cows were kept on pasture at least one of the periods between the 2 daily milkings and at least $40 \%$ of the DMI came directly from the grazing sessions, supplemented with a partial mixed ration.

Three veterinary technicians were hired and trained as research assistants for this experiment. One of these technicians was supported by the first author, and covered 2 dairy farms. The other 2 technicians each covered one of the remaining 2 farms. Technicians enrolled animals, administered experimental treatments, took blood samples, assessed BCS, diagnosed diseases, or confirmed diagnoses made by the farm staff, and were responsible for keeping written records. 


\section{Enrollment and Treatment Allocation}

The time of enrollment in the study was between -10 to $-7 \mathrm{~d}$ relative to the expected calving date. Animals that had fever (rectal temperature $>39.5^{\circ} \mathrm{C}$ ) or any other clinical health disorder at the time of enrollment were excluded from the study. Animals that met the inclusion criteria were assigned to either treatment or untreated control based on their national ear tag number. The national ear tag number is assigned to cattle at birth. The national ear tag numbers are available from computer records but are independent of the large and easily visible ear tag number (cow ID) that is used for on-farm management. Animals with an even national ear tag number were injected with $15 \mathrm{mg}$ of pegbovigrastim (Imrestor, Elanco Animal Health) according to the product label (PEG) and animals with an odd national ear tag number remained as untreated controls (control). The decision to treat the even-numbered cows was based on a single randomization procedure using the toss of a coin. No placebo was used, as treatment allocation based on the national ear tag number provided sufficient blinding, and control and PEG cows were visited and blood sampled using exactly the same protocol, as explained below.

Research technicians applied treatments based on the national ear tag number and would therefore be aware of the treatment status. All animal observations, samplings, and disease diagnoses were based on the visible on-farm cow ID. This on-farm cow ID was unrelated to the national ear tag number that was used for randomization. Farm personnel and veterinarians involved in disease diagnoses, estrus detection, insemination, pregnancy diagnoses, and culling decisions were blinded to treatment status, and only used the visible on-farm cow ID. Electronic readers that might show both tags were not used on any of the farms at any time.

Close-up pens were observed 2 times a week. Cows that were between -10 to $-7 \mathrm{~d}$ relative to the expected calving date or were exhibiting clinical signs of calving such as swelling of the vulva and filling of the udder were clinically examined to rule out exclusion criteria (i.e., fever or any other clinical disease).

Animals assigned to the PEG treatment received a second dose within $24 \mathrm{~h}$ after calving; only cows that received both doses were included in the study. The included animals therefore represent the "meet protocol" inclusion rule (Sargeant et al., 2010).

Control and PEG cows remained in observation for at least $30 \mathrm{~min}$ to record any adverse event due to treatment or handling, both after enrollment and after calving.

\section{Prepartum BCS Assessment, Blood Sampling, and NEFA Determination}

At $\mathrm{d}-10$ to -7 from the expected calving date (enrollment), BCS was assessed (Ferguson et al., 1994) and recorded by each of the veterinary technicians. At the same time, blood samples were collected from the coccygeal vessel (8.5-mL clot accelerator tubes, Becton Dickson). Control and PEG animals were blood sampled again within $24 \mathrm{~h}$ after calving (i.e., when PEG cows also received the second treatment), for further determinations beyond the aim of this report. Blood samples were centrifuged at $3,000 \times g$ for 20 min and serum was stored frozen $\left(-20^{\circ} \mathrm{C}\right)$ until further analysis for NEFA concentrations at the Animal Endocrine and Metabolism Laboratory, Veterinary Faculty, Montevideo, Uruguay. Nonesterified fatty acid concentrations were measured by colorimetric assays on an A25 autoanalyzer (Biosystems S.A.) using commercial kits: Wako NEFA-HR (2) (Wako Pure Chemical Industries Ltd.), as reported before (Barca et al., 2021a,b). Laboratory personnel were blinded to treatment status.

\section{Clinical Diagnoses and Definitions}

For the purpose of this study, the experimental unit was the cow; the follow-up period for all clinical diseases was limited from enrollment until 30 DIM. We only included early-lactation clinical diseases as variables with potential interaction with PEG treatment, because immune stimulation due to PEG is transient (Kimura et al., 2014; McDougall et al., 2017; Van Schyndel et al., 2018) and clinical diseases later in lactation are logically associated with longer herd life, as animals need to be alive in the herd to be able to register disease.

Each veterinary technician was trained before the start of the study to diagnose CM, RP, metritis, and clinical endometritis. At the same time, all farm personnel were trained in the recognition of these disorders and all diagnoses were ultimately confirmed by the trained trial technicians. At 2 postpartum visits, at 5 to 8 and 27 to 30 DIM, all cows were carefully assessed by the veterinary technician to diagnose metritis and clinical endometritis respectively. If metritis and clinical endometritis were diagnosed by the farm personnel at a different time point, this was also recorded and included into the disease categories described hereunder. Clinical mastitis was diagnosed by trained farm personnel while forestripping all quarters of all cows at each milking. Clinical mastitis was scored according to Pinzón-Sánchez and Ruegg (2011) as mild (abnormal milk without other symptoms), moderate (abnormal 
milk and local symptoms in the udder), or severe (abnormal milk, local symptoms, and also signs of systemic illness). All CM cases, irrespective of severity, were combined and reported as CM. Retained placenta was recognized when the fetal membranes (placenta) were visible hanging from the cow's vulva at $24 \mathrm{~h}$ or more after calving (Ruiz et al., 2017). Puerperal metritis was diagnosed if an animal showed a fetid watery red-brown uterine discharge, associated with signs of systemic illness (such as decreased milk yield, dullness, or other signs of toxemia) and fever (rectal temperature $>39.5^{\circ} \mathrm{C}$ or $>40.5^{\circ} \mathrm{C}$ during summer and when ambient temperature was higher than $30^{\circ} \mathrm{C}$; Burfeind et al., 2012) within $21 \mathrm{~d}$ postpartum. Clinical metritis was defined as cows that were not ill, but that had a purulent uterine discharge detectable in the vagina within the first $21 \mathrm{~d}$ after calving. In the present study, puerperal metritis and clinical metritis were combined into one disease code and reported as metritis. Clinical endometritis was the presence of purulent uterine discharge detectable in the vagina $21 \mathrm{~d}$ or more postpartum, or mucopurulent discharge detectable in the vagina more than $26 \mathrm{~d}$ postpartum. Manual vaginal examinations were performed using clean palpation gloves. All uterine diseases were defined according to Sheldon et al. (2006).

\section{Definition of Fertility and Culling Outcomes}

The full set of animals was considered at risk for breeding with 2 exceptions: (1) a cow removed during the voluntary waiting period, defined as a cow that was removed from the study during the first 30 DIM and that was not inseminated. All farms declared a voluntary waiting period of at least 30 DIM; however, if a cow was inseminated before 30 DIM by accident, it was still included in the analysis. (2) The second exception is a "do not breed" cow: a cow that was not inseminated within 305 DIM. We assumed that these animals were considered cows that were not going to be bred (Bewley et al., 2010).

Time to first insemination was defined as the interval in days from calving to the first insemination. We evaluated rate of first insemination with a censoring time of 305 DIM as explained above.

Time to pregnancy was defined as the interval in days from calving to the insemination that led to conception (last insemination before the pregnancy diagnosis). We evaluated rate of pregnancy with 2 censoring times. The first analysis used a censoring time of 150 DIM. This censoring policy was chosen since pregnancy status at 150 DIM was reported as a robust measure of the overall reproductive perfor- mance in commercial dairy farms (Caraviello et al., 2006). We also performed an analysis with a censoring time of 305 DIM.

Time to culling was defined as the interval in days from calving to removal from the herd (i.e., death or sales). The censored end point was either the day of dry-off or end of study, which was August 1, 2019 (529 $\mathrm{d}$ from the first recorded calving in the study and $305 \mathrm{~d}$ from the last recorded calving in the study).

\section{Statistical Analysis}

Data were analyzed using SAS software (2018, SAS University Edition, SAS Institute Inc.).

Descriptive statistics to evaluate balance between treatment groups with regard to prepartum BCS, prepartum NEFA concentration, interval between enrollment and calving, lactation number, previous lactation total milk production, DIM at dry-off, and previous lactation daily milk production were performed using the $t$-test procedure (PROC TTEST). The chi-squared test (PROC FREQ) was used to evaluate balance between treatment groups with regard to season of enrollment, previous lactation CM (yes/no), and SCC at dry-off (high/low). Frequencies of treated and untreated animals grouped by lactation group (lactation 1 , lactation 2 , and lactation $2+$ ), prepartum BCS categories (pre-BCS: under: $<3$; acceptable: 3 to 3.5 , and over: >3.5; Roche et al., 2009), prepartum NEFA class (pre-NEFA: low $\leq 0.3$; high $>0.3 \mathrm{~m} M$, Overton et al., 2017), and animals considered to be at risk for breeding were generated using the frequency procedure (PROC FREQ). The chi-squared test was also used to assess whether treatment group was associated with the frequency of (a) cows excluded from the fertility analysis, (b) cows removed from the herd during the voluntary waiting period and not inseminated, and (c) "do not breed cows."

Rate of first insemination, rate of pregnancy, and hazard of culling analyses were carried out using Cox's proportional hazards regression models (PROC PHREG). A first set of models (model 1) included as fixed effects only pre-treatment covariates. The following were considered as class variables: lactation (lactation 1, lactation 2, and lactation 2+), pre-NEFA, pre-BCS, treatment (control/PEG), and calving month (6 classes: February/March, April, May, June, July, and August/September). Farm, also as a class variable, was included as a random effect. Two-way interactions between covariates and treatment and the 3-way interaction of lactation, pre-NEFA and treatment were checked for significance.

The general model then looked like this: 
hazard of (variable of interest) $=$ baseline hazard

+ lactation + pre-NEFA + pre-BCS + treatment

+ calving month + interactions + farm (random).

A second set of models (model 2) was developed to evaluate the interaction of PEG treatment with clinical disease. Kaplan-Meier univariable analyses were performed to evaluate the association of $\mathrm{CM}, \mathrm{RP}$, metritis, and endometritis with the outcomes of interest. Because RP and metritis occur sequentially and close together in time, and we have previously detected a strong association between these uterine diseases (Barca et al., 2021b), we also grouped them in a new category recorded as uterine disease (UD, i.e., a cow with a record of RP, metritis, or both). In case that $\mathrm{RP}$ and metritis were simultaneously associated with an outcome of interest, we evaluated UD, and if it was also associated with the outcome of interest, we used UD only. The grouping methodology was identical to the one reported by Carvalho et al. (2019). This was done to avoid potential multicollinearity (correlated independent variables) in the models. Clinical events that were associated at a $P<0.2$ were included in the multivariable modeling process.

The second general model then looked like this:

$$
\begin{gathered}
\text { hazard of (interest variable) }=\text { baseline hazard } \\
+ \text { lactation }+ \text { pre-NEFA }+ \text { pre-BCS }+ \text { treatment } \\
+ \text { calving month }+\mathrm{CM}+\mathrm{RP}+\text { metritis }(\text { or }+\mathrm{UD}) \\
+ \text { endometritis }+ \text { interactions }+ \text { farm (random) }
\end{gathered}
$$

The interaction of treatment with a clinical event was always evaluated, and 2- and 3-way interactions of lactation and pre-NEFA with treatment were checked.

Because of our previous observation on the importance of prepartum NEFA concentration in PEGtreated animals (Barca et al., 2021a,b), the effects of parity (primiparous/multiparous), pre-NEFA, and the potential clinical disease by treatment interaction were evaluated using stratified data sets. We stratified the data by parity (primiparous and multiparous) and preNEFA.

With the exception of the stratified data by parity, lactation as a covariate was grouped in 3 categories (lactation 1, lactation 2, and lactation 2+) because this categorization produced a better fit of models (smaller Akaike information criterion number) than using just 2 categories (lactation 1 and lactation 1+).

Modeling was done using a manual forward selection procedure and only variables or their interaction with a $P \leq 0.10$ were included in the model. Statistical tendency was defined at $P \leq 0.10$ and statistical significance at $P \leq 0.05$. The assumption of proportional hazards was evaluated using graphical assessment of observed and predicted survival. For ease of interpretation, in the Results and Discussion, the hazard rate is presented as rate in case of time to first insemination and time to pregnancy and as hazard in case of time to culling. The outputs of the final models are presented and the hazard ratio (HR) for each variable or interaction provided. Compared with an unspecified baseline hazard function (HR with all covariates set to the reference groups), a HR $>1$ means that an event occurs sooner, whereas a HR $<1$ means that an event will occur later (Cox, 1972). Survival curves illustrating the most important findings are presented.

\section{RESULTS}

\section{Study Population and Balance Between Treatment Groups}

Initially 2,336 cows were assessed for enrollment on the 4 farms; out of those, 3 cows (control $=2 ; \mathrm{PEG}=1$ ) were excluded because they had fever (rectal temperature $>39.5^{\circ} \mathrm{C}$ ) or another clinical health disorder at the time of enrollment. Out of the 2,333 initially enrolled cows, 2,153 (primiparous cows $=733$; control $=391$, $\mathrm{PEG}=342$ and multiparous cows $=1,420$; control $=$ $723, \mathrm{PEG}=697$ ) met the protocol inclusion rule (Barca et al., 2021b). No adverse events due to treatment or handling were recorded. Table 1 shows descriptive data for the enrolled cows by treatment group: season of enrollment, prepartum BCS, prepartum NEFA concentration, the interval in days between enrollment and calving (in case of PEG this is the interval between PEG doses), and lactation number of the enrolled cows after calving. For multiparous cows, descriptive data of the previous lactation included lactation number at enrollment, previous total milk production, DIM at dry-off, daily milk production, proportion of cows with one or more CM cases, and proportion of cows with high SCC (>200,000 cell/mL) at dry-off. No differences between treatment groups at the time of enrollment were found in any of these variables. No difference between treatment groups was found regarding prepartum NEFA concentration by pre-NEFA class: low: control $=0.18$ $\pm 0.07 \mathrm{~m} M ;$ PEG $=0.18 \pm 0.07 \mathrm{~m} M ; P=0.50$; high: control $=0.71 \pm 0.37 \mathrm{~m} M ;$ PEG $=0.73 \pm 0.41 \mathrm{~m} M$; $P=0.26$; or in the number of cows in each pre-NEFA class in each treatment group: low: control $=435$; PEG $=408$; high: control $=679 ; \mathrm{PEG}=631 ; P=0.92$. In addition, no difference between treatment groups was found by pre-NEFA class within each farm $(P \geq 0.45)$. Figure 1 shows the total number of included animals in 
the control and PEG group by lactation group and preNEFA class. Out of the 2,153 cows, $7.0 \%$ of the cows (control $=3.5 \% ; \mathrm{PEG}=3.5 \% ; P=0.72$ ) were excluded from the fertility analysis because they were removed from the herd during the voluntary waiting period and not inseminated (control $=4.2 \%$; PEG $=3.1 \%$; $P=$ 0.72 ) or were defined as "do not breed cow" (control = $2.9 \% ; \mathrm{PEG}=4.4 \% ; P=0.07)$.

Prepartum BCS, as a class variable, was not associated with any outcome analyzed in this study and did not remain in the statistical models.

\section{Effect of Treatment with Pegbovigrastim on Rate of First Insemination}

In total, 1,835 out of $2,002(91.7 \%)$ cows that were considered at risk for breeding were inseminated. The mean and standard deviation of time to first insemination was $80 \pm 39$ DIM and the range was 3 to 305 DIM. Out of these 1,835 cows, $14(0.8 \%)$ cows were inseminated within 30 DIM. Kaplan-Meier analyses showed that $\mathrm{CM}$ and metritis were sufficiently associated $(P$ $<0.2)$ with rate of first insemination to include in the multivariable modeling process.

The differences in PEG treatment results between Cox proportional hazards model 1 (only pre-treatment variables) and model 2 (pre-treatment variables + clinical disease) were minor, so we only present the outcome of model 2 in the main body of this paper. Model 1 is presented in Supplemental Table S2 (http://dx.doi .org/DOI:10.17632/ftkm7775kn.3, Barca, 2021).

In the Cox proportional hazards regression model for first insemination, we found an interaction between pre-NEFA and PEG treatment, as high pre-NEFA cows, when treated with PEG, showed an increased rate of first insemination $(\mathrm{HR}=1.25, P=0.02$, Table 2, Figure 2). Clinical mastitis was associated with a decreased rate of first insemination $(\mathrm{HR}=0.79, P<$ 0.001). Metritis by itself was not associated with the rate of first insemination but interacted with preNEFA, as high pre-NEFA cows with metritis showed a decreased rate of first insemination $(\mathrm{HR}=0.75, P$ $=0.03)$.

\section{Effect of Treatment with Pegbovigrastim on Rate of Pregnancy}

In total, 1,325 out of $2,002(66.2 \%)$ cows that were considered at risk for breeding were identified as pregnant. Of these 1,325 cows, $35(2.6 \%)$ became pregnant beyond 305 DIM, and were thus censored at 305 DIM in our analyses. At 150 DIM, 1,028 (51.3\%) cows were pregnant, whereas at 305 DIM this was 1,290 (64.4\%).
The mean and standard deviation of time to pregnancy in all 1,325 analyzed cows was $114 \pm 56$ DIM and the range was 17 to 305 DIM. When censoring either at 150 DIM or 305 DIM, Kaplan-Meier analyses showed that CM, RP, metritis, UD, and endometritis were sufficiently associated $(P<0.2)$ with rate of pregnancy to include in the multivariable modeling process. As RP and metritis were both associated with rate of pregnancy, and UD was also associated with pregnancy, only the latter was used in the multivariable modeling process.

The Cox proportional hazards regression model 1 (pre-treatment variables only) for pregnancy, censored at 150 or 305 DIM, did not show treatment effects (Supplemental Table S2).

Table 3 presents the Cox proportional hazards regression model 2 (with pre-treatment variables and clinical disease) for pregnancy. Censoring at 150 DIM, we found a 3 -way interaction pre-NEFA by treatment by UD. High pre-NEFA tended to be associated with decreased rate of pregnancy $(\mathrm{HR}=0.87, P=0.09)$ and UD was also associated with decreased rate of pregnancy ( $\mathrm{HR}=0.74, P=0.02)$, whereas high preNEFA PEG-treated cows that subsequently recorded UD showed an increased rate of pregnancy $(\mathrm{HR}=1.55$, $P=0.005)$. Clinical mastitis was associated with decreased rate of pregnancy $(\mathrm{HR}=0.69, P<0.001)$ and endometritis tended to be associated with decreased rate of pregnancy $(\mathrm{HR}=0.71, P=0.06)$.

Within 305 DIM, the Cox proportional hazards regression model 2 for pregnancy (Table 3 ) showed that UD was associated with decreased rate of pregnancy (HR $=0.78, P=0.01)$ and we found that PEG-treated cows that subsequently recorded UD tended to show an increased rate of pregnancy $(\mathrm{HR}=1.30, P=0.06)$. Clinical mastitis and endometritis were associated with a decreased rate of pregnancy $(\mathrm{HR}=0.75, P<0.001$ and $\mathrm{HR}=0.74, P=0.05$, respectively). When endometritis was removed from the model, the treatment by UD interaction became significant $(\mathrm{HR}=1.32, P$ $=0.04$ ).

\section{Effect of Treatment with Pegbovigrastim on Hazard of Culling}

During the study period, 425 out of 2,153 (19.7\%) cows were removed from the herd (i.e., death or sales). The mean and standard deviation of time to removal was $187 \pm 130$ DIM and the range was 0 to 491 DIM. Out of these 425 cows, 88 cows $(20.7 \%)$ were culled after 305 DIM. Kaplan-Meier analyses showed that CM and metritis were sufficiently associated $(P<0.2)$ with hazard of culling to include in the multivariable modeling process. 
Barca et al.: PEGBOVIGRASTIM: FERTILITY AND CULLING

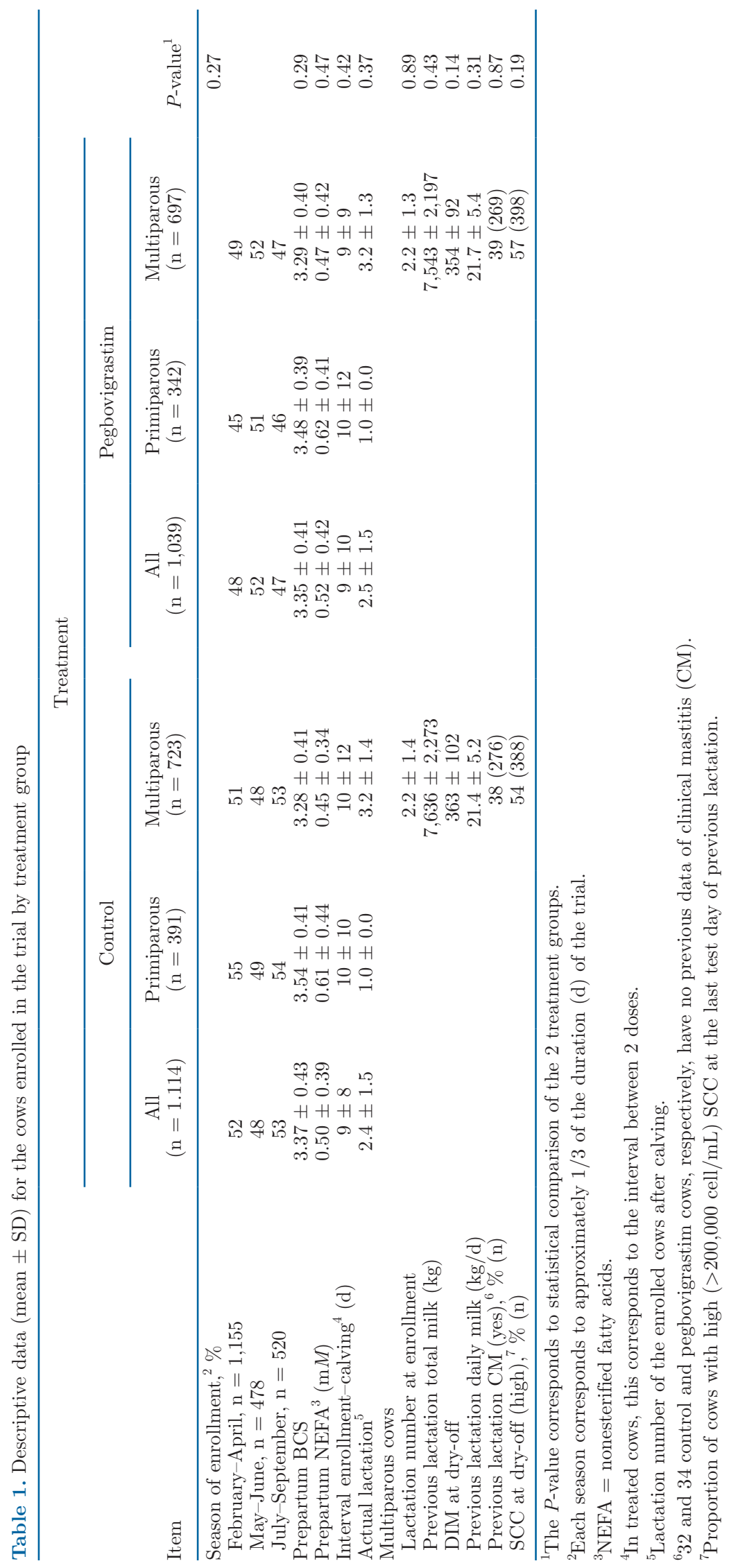




\section{Included cows}

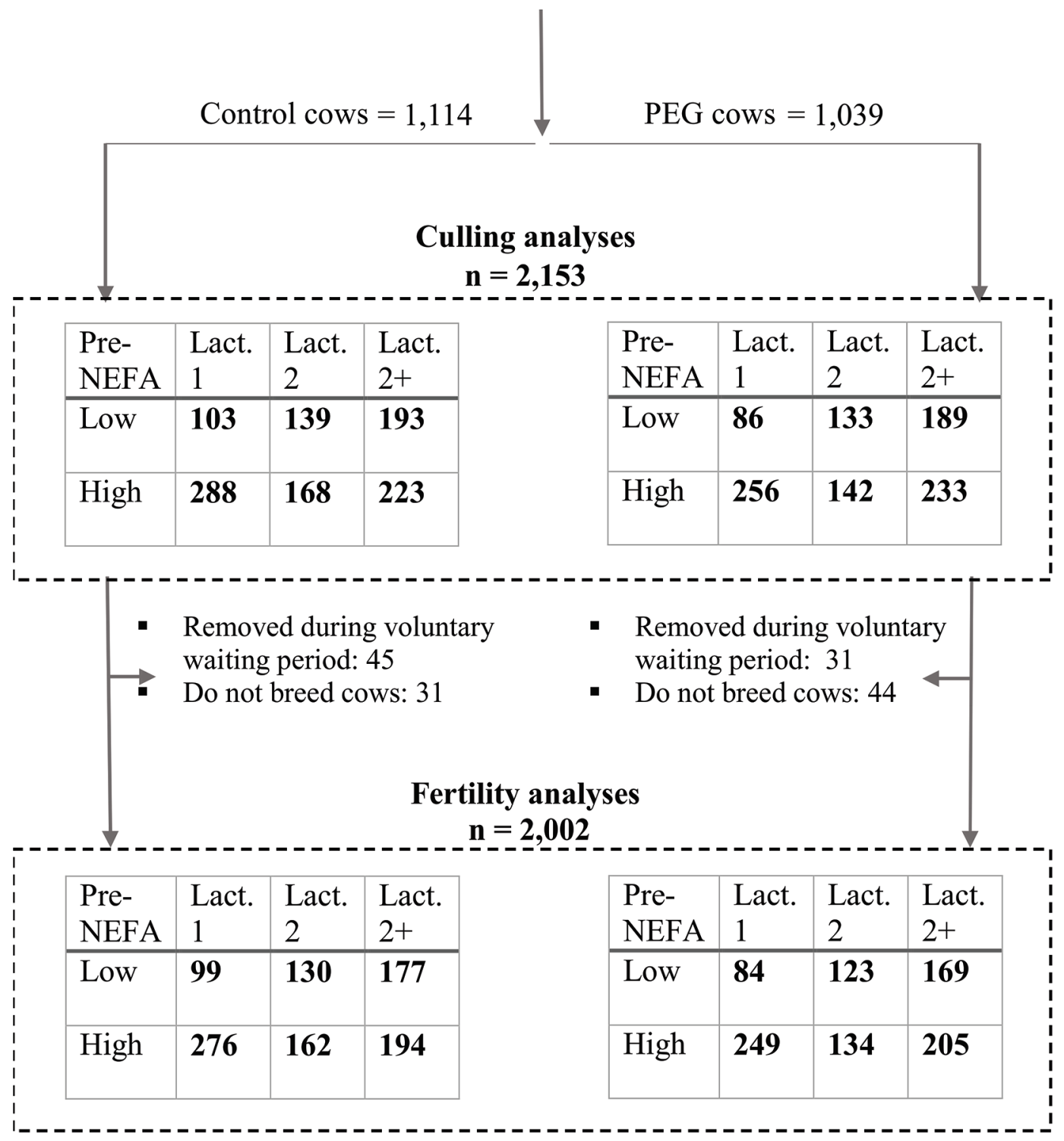

Figure 1. Total included cows and cows that were considered for fertility analyses. Low pre-NEFA $\leq 0.3 \mathrm{~m} M>$ high pre-NEFA. Lact. $=$ lactation; PEG = pegbovigrastim; NEFA $=$ nonesterified fatty acids.

Because no differences were found in the treatment results between model 1 (pre-treatment variables only; Supplemental Table S2) and model 2 (pre-treatment variables and clinical diseases), we only present the latter.

Table 4 presents the Cox proportional hazards regression model 2 for culling. We found a tendency for pre-NEFA by treatment interaction. High pre-NEFA was associated with increased hazard of culling $(\mathrm{HR}=$ $1.42, P=0.02)$, whereas high pre-NEFA PEG-treated cows tended to show a decreased hazard of culling (HR $=0.71, P=0.09)$. Clinical mastitis and metritis were associated with increased hazard of culling $(\mathrm{HR}=1.99$, $P<0.001$ and $\mathrm{HR}=1.32, P=0.02$, respectively).

\section{Effect of Treatment with Pegbovigrastim on Rate of First Insemination, Rate of Pregnancy, and Hazard of Culling Stratified by Prepartum NEFA Class and Parity}

When performing the Cox proportional hazards regression model for first insemination on stratified data, in the stratum of high pre-NEFA cows (Table 5), we found that PEG increased the rate of first insemination 
Table 2. Cox proportional hazards regression model of first insemination including pre-treatment variables and clinical disease $(\text { control }=1,038 ; \text { pegbovigrastim }=964)^{1}$

\begin{tabular}{lcccc}
\hline Item & Estimate & SE & $P$-value & Hazard ratio \\
\hline Lactation & & & & \\
1 & 0.06 & 0.06 & 0.33 & 1.06 \\
$2+$ & -0.12 & 0.08 & 0.04 & 0.89 \\
Pre-NEFA & -0.13 & 0.08 & 0.11 & 0.88 \\
Treatment & -0.08 & 0.08 & 0.29 & 0.92 \\
Calving month & & & 0.002 & 0.79 \\
Clinical mastitis & -0.23 & 0.07 & $<0.001$ & 1.12 \\
Metritis & 0.11 & 0.11 & 0.31 & 1.25 \\
Pre-NEFA $\times$ treatment & 0.22 & 0.10 & 0.02 & 0.75 \\
Metritis $\times$ pre-NEFA & -0.29 & 0.13 & 0.03 & \\
\hline
\end{tabular}

${ }^{1}$ Reference groups: lactation 2, low pre-nonesterified fatty acids (NEFA; $\leq 0.3 \mathrm{mM}$ ), control, calving mo 4 , no clinical mastitis, and no metritis.

${ }^{2}$ Overall $P$-value for all calving month classes (type III test).

$(\mathrm{HR}=1.15, P=0.02)$, whereas $\mathrm{CM}$ and metritis were associated with decreased rate of first insemination (HR $=0.77, P=0.003$ and $\mathrm{HR}=0.85, P=0.03$, respectively). No treatment effect was detected in the stratum of low pre-NEFA cows (Supplemental Table S3, http:// dx.doi.org/DOI:10.17632/ftkm7775kn.3, Barca, 2021). Stratifying by parity group (Supplemental Table S3), we found a tendency for pre-NEFA by treatment interaction in multiparous cows, as multiparous high preNEFA PEG-treated cows tended to show an increased rate of first insemination $(\mathrm{HR}=1.25, P=0.07)$. No treatment effect was detected in primiparous cows.

Cox proportional hazards regression model for pregnancy within 150 DIM showed that, in high pre-NEFA cows (Table 5), CM was strongly associated with decreased rate of pregnancy $(\mathrm{HR}=0.49, P<0.001)$, whereas PEG-treated cows that subsequently recorded $\mathrm{CM}$ showed an increased rate of pregnancy $(\mathrm{HR}=1.75$,

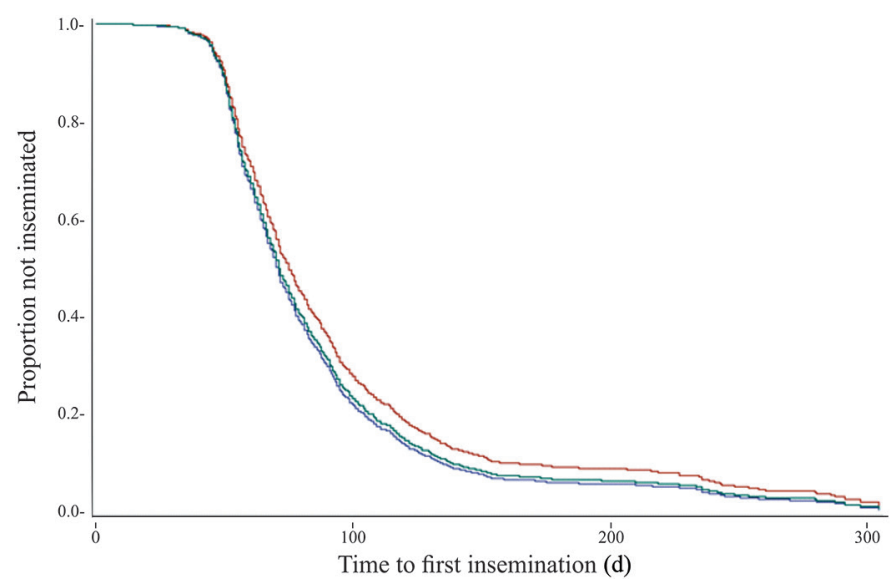

Figure 2. Survival curves of time to first insemination for low preNEFA control cows $(n=406$, blue line), high pre-NEFA control cows $(\mathrm{n}=632$, red line), and high pre-NEFA pegbovigrastim (PEG) cows ( $\mathrm{n}$ $=588$; green line). Low pre-NEFA $\leq 0.3 \mathrm{~m} M>$ high pre-NEFA. NEFA $=$ nonesterified fatty acids.
$P=0.04$ ). Figure 3 (panel A) illustrates the treatment by $\mathrm{CM}$ interaction in high pre-NEFA cows. Uterine disease tended to be associated with decreased rate of pregnancy $(\mathrm{HR}=0.78, P=0.08)$ and PEG-treated cows that subsequently recorded UD tended to show an increased rate of pregnancy $(\mathrm{HR}=1.45, P=0.06)$. Endometritis tended to be associated with decreased rate of pregnancy $(\mathrm{HR}=0.70, P=0.09)$. When endometritis was removed from the model, the negative association of UD with rate of pregnancy $(\mathrm{HR}=0.75$, $P=0.04)$ as well as the treatment by UD interaction $(\mathrm{HR}=1.46, P=0.05)$ became statistically significant. Figure 3 (panel B) illustrates the treatment by UD interaction in high pre-NEFA cows. No treatment effects were detected in low pre-NEFA cows or in separate parity groups (Supplemental Table S3).

For the model of pregnancy within 305 DIM, we found that high pre-NEFA PEG-treated cows that subsequently recorded UD tended to show an increased rate of pregnancy $(\mathrm{HR}=1.36, P=0.07$; Table 5). Clinical mastitis was associated with a decreased rate of pregnancy (HR $=0.71, P=0.003)$ and endometritis tended to be associated with decreased rate of pregnancy $(\mathrm{HR}=0.75, P=0.10)$. No treatment effects were detected in low pre-NEFA cows (Supplemental Table S3). In multiparous cows, UD was associated with decreased rate of pregnancy $(\mathrm{HR}=0.77, P=$ 0.05 ) and we found that multiparous cows treated with PEG that subsequently recorded UD tended to show an increased rate of pregnancy $(\mathrm{HR}=1.38, P=0.08)$. No treatment effects were detected in primiparous cows (Supplemental Table S3).

When performing the Cox proportional hazards regression model for culling on stratified data, in high pre-NEFA cows (Table 5), we found that treatment with PEG decreased the hazard of culling $(\mathrm{HR}=0.79$, $P=0.05)$, whereas $\mathrm{CM}$ and metritis were associated with increased hazard of culling $(\mathrm{HR}=2.02, P<0.001$ 
Table 3. Cox proportional hazards regression model of pregnancy including pre-treatment variables and clinical diseases (control $=1,038$; PEG $=964)^{1}$

\begin{tabular}{|c|c|c|c|c|c|c|c|c|}
\hline \multirow[b]{2}{*}{ Item } & \multicolumn{4}{|c|}{ Censored at 150 DIM } & \multicolumn{4}{|c|}{ Censored at 305 DIM } \\
\hline & Estimate & $\mathrm{SE}$ & $P$-value & $\begin{array}{c}\text { Hazard } \\
\text { ratio }\end{array}$ & Estimate & $\mathrm{SE}$ & $P$-value & $\begin{array}{c}\text { Hazard } \\
\text { ratio }\end{array}$ \\
\hline \multicolumn{9}{|l|}{ Lactation } \\
\hline 1 & 0.16 & 0.08 & 0.04 & 1.18 & 0.13 & 0.07 & 0.06 & 1.14 \\
\hline $2+$ & -0.22 & 0.08 & 0.006 & 0.80 & -0.26 & 0.07 & $<0.001$ & 0.77 \\
\hline Pre-NEFA & -0.14 & 0.08 & 0.09 & 0.87 & & & & \\
\hline Uterine disease & -0.30 & 0.10 & 0.002 & 0.74 & -0.25 & 0.10 & 0.01 & 0.78 \\
\hline Endometritis & -0.34 & 0.18 & 0.06 & 0.71 & -0.29 & 0.15 & 0.05 & 0.74 \\
\hline Treatment $\times$ uterine disease & - & - & - & - & 0.26 & 0.14 & 0.06 & 1.30 \\
\hline Pre-NEFA $\times$ treatment $\times$ uterine disease & 0.44 & 0.16 & 0.005 & 1.55 & - & - & - & - \\
\hline
\end{tabular}

${ }^{1}$ Reference groups: lactation 2, low pre-nonesterified fatty acids (NEFA; $\leq 0.3 \mathrm{mM}$ ), control, no clinical mastitis, no uterine disease, and no endometritis.

and $\mathrm{HR}=1.32, P=0.05$, respectively). No treatment effects were found in low pre-NEFA cows (Supplemental Table S3). Figure 4 (panel A) illustrates the effect of PEG treatment on time to culling.

In multiparous cows, we found that PEG treatment tended to counteract the negative association between $\mathrm{CM}$ and hazard of culling. Clinical mastitis was strongly associated with increased hazard of culling $(\mathrm{HR}=2.61$, $P<0.001$ ), whereas cows treated with PEG that subsequently recorded a $\mathrm{CM}$ case tended to show a decreased hazard of culling $[\mathrm{HR}=0.62, P=0.06$, Figure 4 (panel B)]. No treatment effects were detected in primiparous cows (Supplemental Table S3).

\section{DISCUSSION}

This study reports for the first time the effect of PEG on fertility and culling during a full lactation in grazing dairy cows. The main finding was the presence of an interaction between pre-NEFA and treatment. In high pre-NEFA cows, PEG increased the rate of first insemination and counteracted the negative association of early-lactation CM and UD with the rate of preg- nancy within 150 DIM. Similarly, in high pre-NEFA cows, PEG treatment decreased the hazard of culling.

Treatment with PEG did not affect the overall rate of first insemination, but interacted with pre-NEFA, as PEG increased the rate of first insemination only in high pre-NEFA cows. Previous studies showed that PEG increased the rate of insemination within 100 DIM by $5.8 \%$ (Ruiz et al., 2017), whereas no effect was reported within 120 DIM when only cows in an optimal BCS were included (Zinicola et al., 2018), or within 150 DIM when including cows with no restrictions based on BCS (Van Schyndel et al., 2021). We are not aware of other studies showing that the effect of PEG on the rate of first insemination is associated with lipid mobilization in cows. As the pre-NEFA by treatment interaction effect on rate of first insemination remained unchanged in the statistical models with or without clinical diseases, our data would suggest that reduction in occurrence of clinical disease (Barca et al., 2021b) is not the only mechanism by which PEG treatment increases the rate of first insemination in high preNEFA cows. Treatment with PEG causes an increase in white blood cell counts during the critical period

Table 4. Cox proportional hazards regression model of culling (i.e., death or sales) including pre-treatment variables and clinical diseases (control $=1,114$; pegbovigrastim $=1,039)^{1}$

\begin{tabular}{lrccc}
\hline Item & Estimate & $\mathrm{SE}$ & $P$-value & Hazard ratio \\
\hline Lactation & & & & \\
1 & -0.06 & 0.15 & 0.67 & 0.94 \\
$2+$ & 0.80 & 0.13 & $<0.001$ & 2.23 \\
Pre-NEFA & 0.35 & 0.15 & 0.02 & 1.42 \\
Treatment & 0.10 & 0.16 & 0.53 & 1.10 \\
Clinical mastitis & 0.69 & 0.11 & $<0.001$ & 1.99 \\
Metritis & 0.28 & 0.12 & 0.02 & 1.32 \\
Pre-NEFA $\times$ treatment & -0.34 & 0.20 & 0.09 & 0.71 \\
\hline
\end{tabular}

${ }^{1}$ Reference groups: lactation 2 , low pre-nonesterified fatty acids (NEFA; $\leq 0.3 \mathrm{mM}$ ), control, no clinical mastitis, and no metritis. 
around calving (Kimura et al., 2014; McDougall et al., 2017; Van Schyndel et al., 2018), when NEB impairs the immune response (Trevisi and Minuti, 2018; Gross and Bruckmaier, 2019). We recently reported that PEG treatment reversed the negative association of prepartum NEFA with postpartum neutrophil counts (Barca et al., 2021a). This could potentially decrease the effect of early-lactation subclinical disease, which is also negatively associated with fertility (Sheldon et al., 2006; Dolecheck et al., 2019). In a small study it was observed that PEG treatment was associated with lower postpartum NEFA concentration (Kimura et al., 2014). Lüttgenau et al. (2016) showed a negative association between postpartum NEFA concentration and rate of insemination. Therefore, the pre-NEFA by treatment interaction identified in the model for rate of first insemination, which remained significant with and without clinical disease, could be explained by a reduction in subclinical disease or by a direct PEG effect on energy metabolism.

Treatment with PEG did not directly affect the rate of pregnancy within 150 DIM or 305 DIM, and there was no interaction of treatment with pre-NEFA. Similarly, no effect of PEG on rate of pregnancy was reported in earlier studies (Zinicola et al., 2018; Van Schyndel et al., 2021). Interestingly, in high pre-NEFA cows, PEG treatment counteracted the negative association of UD with rate of pregnancy within 150 DIM, as shown by the 3-way interaction in the model 2, whereas for pregnancy within 305 DIM, PEG tended to counteract this negative association regardless of preNEFA, as shown by the 2-way interaction in the model 2. Further analyses on stratified data showed that this PEG treatment effect occurred predominantly in high pre-NEFA cows. In high pre-NEFA cows that subsequently recorded $\mathrm{CM}$ and $\mathrm{UD}$, treatment with PEG respectively increased and tended to increase the rate of pregnancy within 150 DIM. As endometritis may be considered a consequence of previous uterine clinical events, we removed it from the model to estimate the total effect of UD on pregnancy (Toni et al., 2015). By removing endometritis from the model, the association of UD and the treatment by UD interaction became significant; therefore, we interpret endometritis as

Table 5. Cox proportional hazards regression model of first insemination, pregnancy (control $=632$; pegbovigrastim, PEG $=588$ ), and culling (i.e., death or sales; control $=679 ; \mathrm{PEG}=631$ ) in high pre-nonesterified fatty acids (NEFA; $>0.3 \mathrm{~m} M$ ) cows, including pre-treatment variables and clinical disease

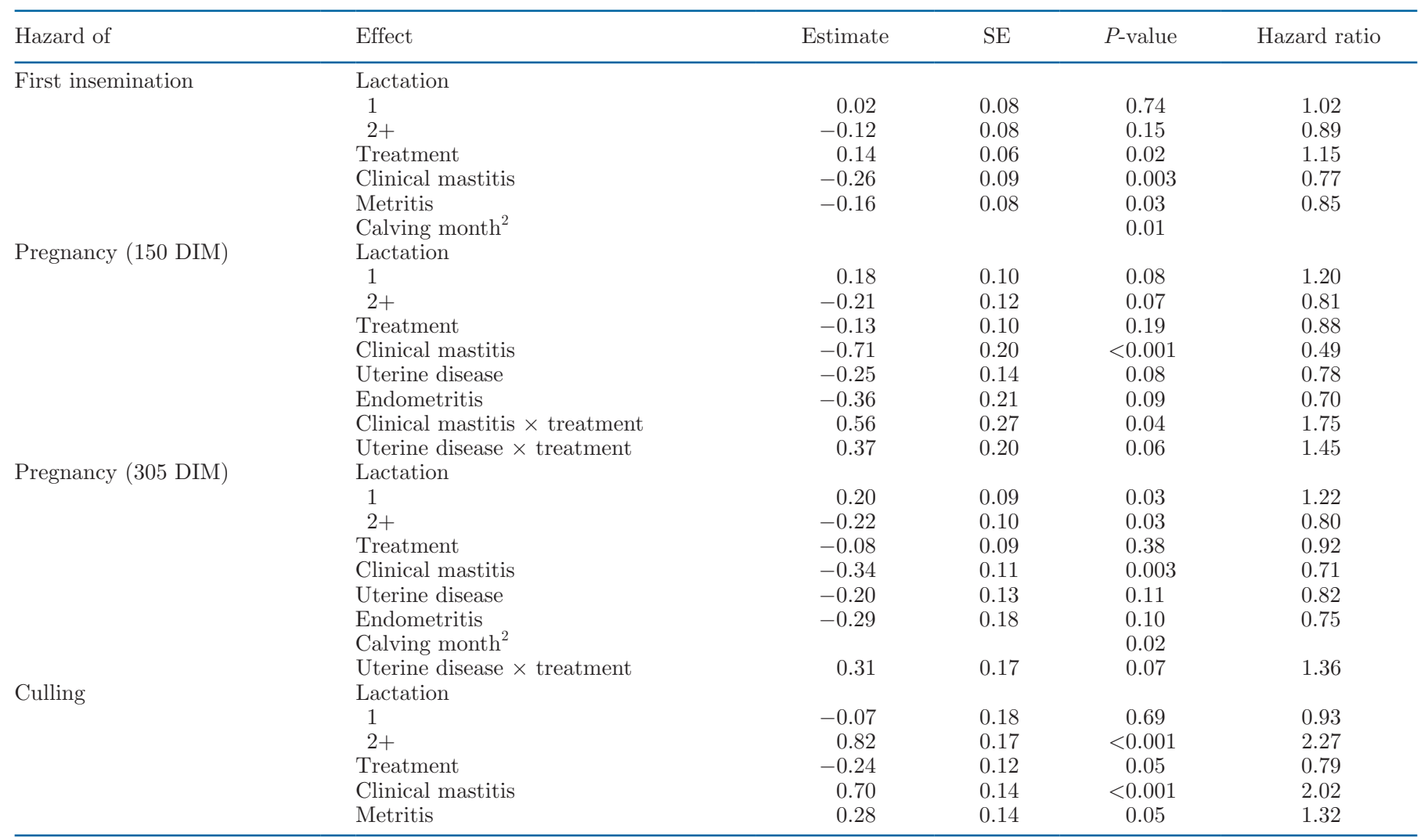

${ }^{1}$ Reference groups: lactation 2, control, no clinical mastitis, no metritis, no uterine disease, no endometritis, and calving mo 4.

${ }^{2}$ Overall $P$-value for all calving month classes (type III test). 

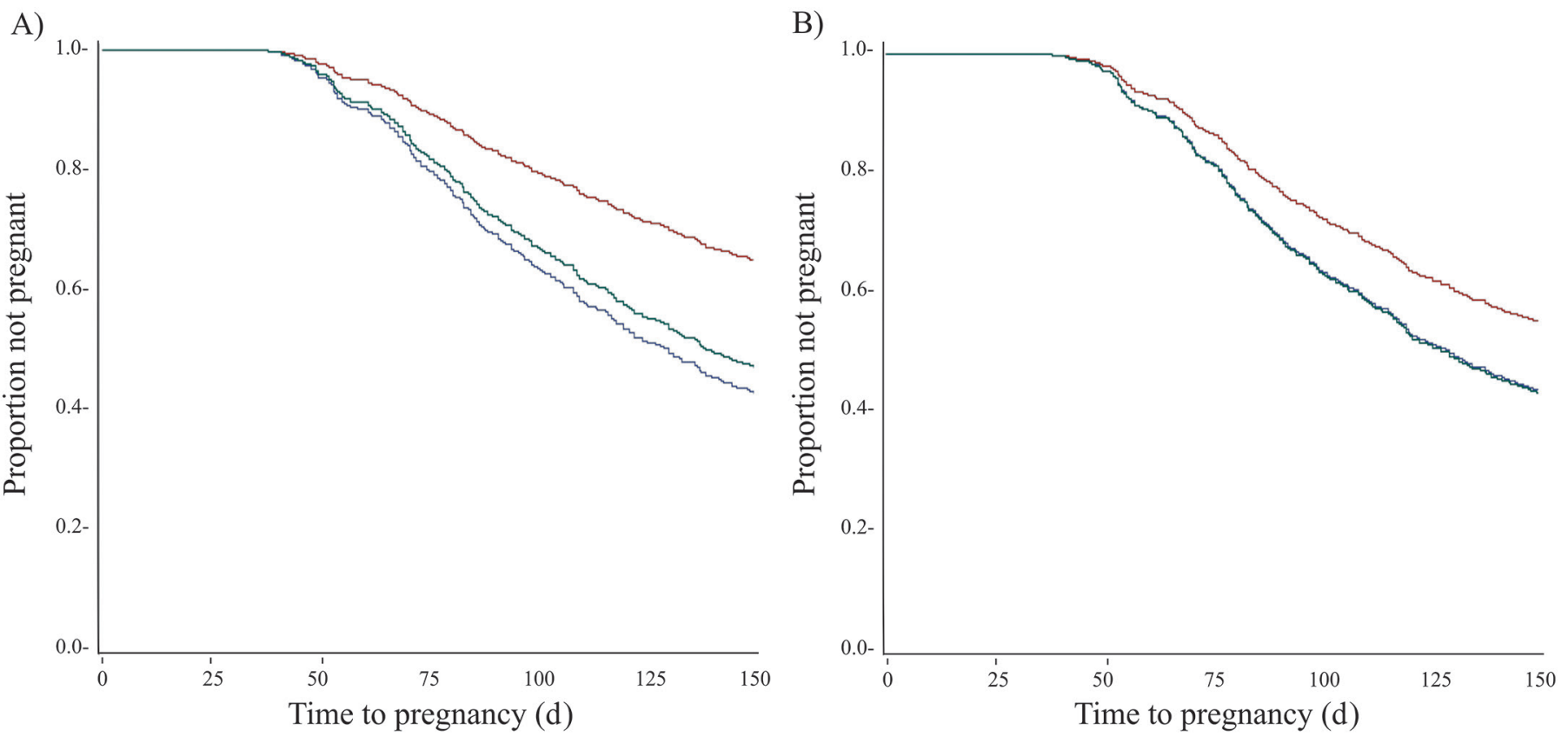

Figure 3. Survival curves of time to pregnancy. (A) Low pre-NEFA control cows without clinical mastitis ( $\mathrm{n}=344$; blue line), high pre-NEFA control cows with clinical mastitis $(\mathrm{n}=105$; red line), and high pre-NEFA pegbovigrastim (PEG) cows with clinical mastitis $(\mathrm{n}=90$; green line). (B) Low pre-NEFA control cows without uterine disease $(\mathrm{n}=333$; blue line), high pre-NEFA control cows with uterine disease $(\mathrm{n}=149$; red line), and high pre-NEFA PEG cows with uterine disease $(n=168$; green line). Note: blue and green lines are virtually overlapping. Uterine disease: a cow with a record of retained placenta, metritis, or both. Low pre-NEFA $\leq 0.3 \mathrm{~m} M>$ high pre-NEFA. NEFA = nonesterified fatty acids.
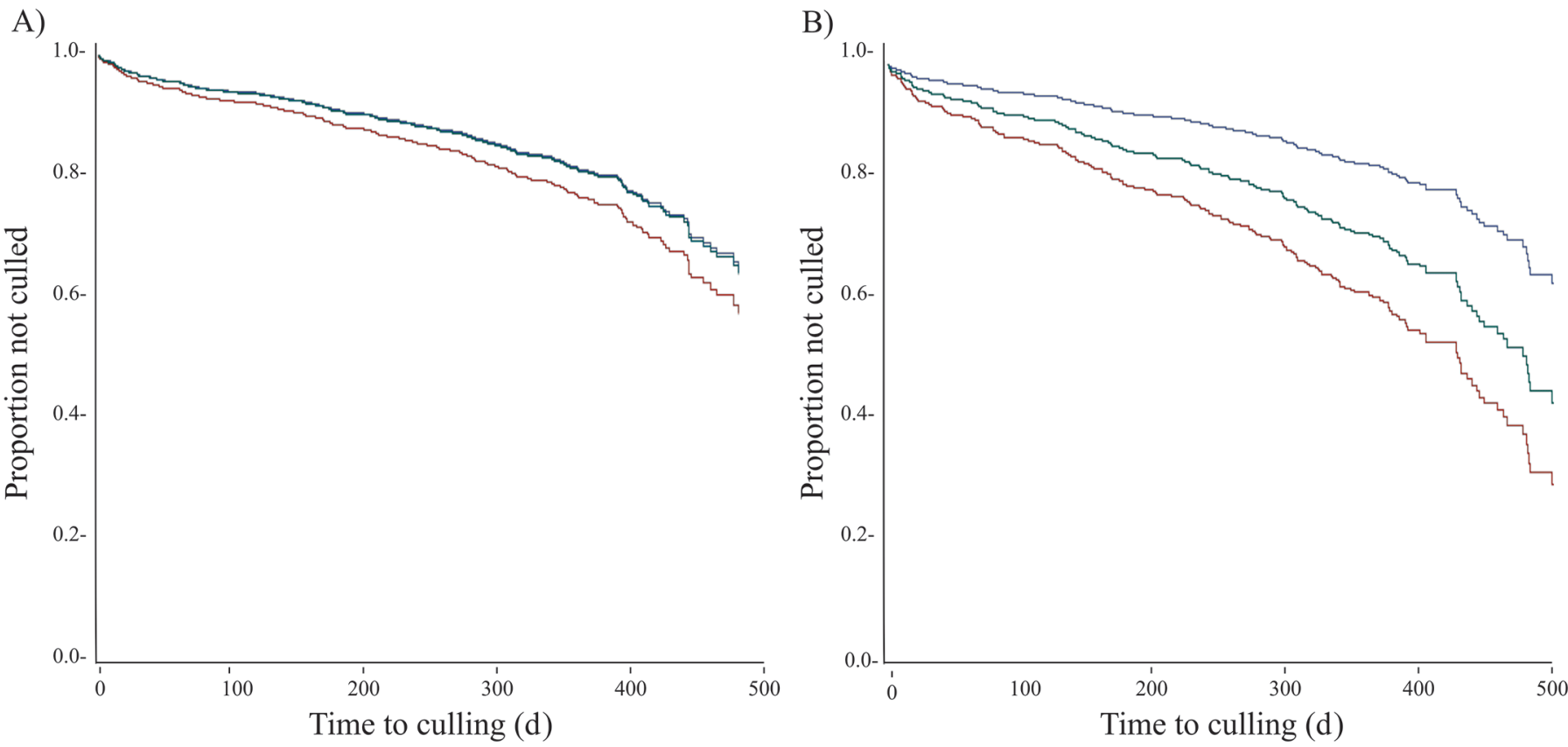

Figure 4. Survival curves of time to culling (i.e., death or sales). (A) Low pre-NEFA control cows ( $\mathrm{n}=435$, blue line), high pre-NEFA control cows $(\mathrm{n}=679$, red line), high pre-NEFA pegbovigrastim $(\mathrm{PEG})$ cows $(\mathrm{n}=631$, green line). Low pre-NEFA $\leq 0.3 \mathrm{~m} M>$ high pre-NEFA. Note: blue and green lines are virtually overlapping. (B) Multiparous control cows without clinical mastitis $(\mathrm{n}=589$, blue line), multiparous control cows with clinical mastitis $(\mathrm{n}=134$, red line), and multiparous PEG cows with clinical mastitis $(\mathrm{n}=111$, green line). NEFA $=$ nonesterified fatty acids. 
an intervening variable between UD and subsequent pregnancy. Consequently, we conclude that PEG significantly counteracted the negative association of UD with rate of pregnancy, which is consistent with our finding that PEG reduced endometritis occurrence in cows that had previous metritis (Barca et al., 2021b). Fourichon et al. (2000), in a meta-analysis, reported that RP was associated with a slight increase in days to first insemination and resulted in a more evident delay in days to pregnancy, whereas metritis consistently increased both days to first insemination and days to pregnancy. Carvalho et al. (2019) reported that, although UD was not associated with rate of first insemination, it was associated with rate of pregnancy and suggested that long-term effects of UD extend beyond the first postpartum insemination. These studies indicate that it is likely that early postpartum UD has a long-term impact on the uterine environment, resulting in lower conceptus viability. In high pre-NEFA cows with CM, we only detected an effect of PEG treatment on the hazard of pregnancy within 150 DIM, and not for 305 DIM. At the same time, the data suggest that the interaction of PEG and UD also appears to be stronger for pregnancy within 150 DIM than within 305 DIM. This suggests that early improvement of the immune response due to PEG contributes to a rapid resolution of postpartum inflammatory processes, which has been proposed as a mechanism to achieve subsequent successful fertility (Bradford et al., 2015). Our data are consistent with our hypothesis that PEG treatment restores immune function in cows with elevated prepartum NEFA concentration (Barca et al., 2021a). The ability to recruit neutrophils into the mammary gland and into the endometrium soon after calving is essential for mastitis resolution, uterine involution, and subsequent fertility (Schukken et al., 2011; Gilbert and Santos, 2016). Powell et al. (2018) showed that PEG primed neutrophils for quick recruitment to the infected mammary gland and Ruiz et al. (2017) suggested higher neutrophil influx into the uterus due to PEG treatment. In multiparous cows that subsequently recorded UD, PEG tended to increase the rate of pregnancy within 305 DIM 1.38 times, counteracting the negative association between UD and rate of pregnancy. Toni et al. (2015) found that metritis resulted in lower fertility only in multiparous cows and suggested that this was a consequence of lower immune function in these older cows. Therefore, it is possible that treatment with PEG is more beneficial for cows with UD in their second and higher lactation.

Treatment with PEG did not affect the overall hazard of culling, but in the high pre-NEFA stratum, PEG resulted in a lower hazard of culling, reinforcing the concept that PEG treatment is beneficial particularly in metabolically challenged cows. A lack of effect on the hazard of culling during the first 63 DIM and 180 DIM has been reported (Van Schyndel et al., 2021; Zinicola et al., 2018, respectively). In these studies, the prepartum NEFA concentration by treatment interaction was not assessed. Interestingly, both Zinicola et al. (2018) and Van Schyndel et al. (2021), in randomly chosen subsets of cows, reported low prepartum NEFA concentrations, well under $0.3 \mathrm{~m} M$. In our data, prepartum NEFA concentration was $\sim 0.50 \pm 0.40 \mathrm{~m} M$, whereas $61 \%$ of the cows had a prepartum NEFA concentration above 0.3 $\mathrm{m} M$. Moreover, we found an incidence of $\mathrm{CM}$ during the first 30 DIM that was more than 4 times higher than in both cited studies. The elevated prepartum NEFA concentration, the relatively high incidence of $\mathrm{CM}$, and the follow-up during the full lactation, especially important for culling (Ribeiro et al., 2016; Carvalho et al., 2019), may explain apparent differences between the studies. As expected, CM was associated with increased hazard of culling (Kossaibati and Esslemont, 1997; Bar et al., 2008; Hertl et al., 2018). However, the reduction of CM in PEG-treated cows, particularly in those with an elevated prepartum NEFA concentration (Barca et al., 2021b), may be only a partial explanation for the finding of a decreased hazard of culling in high pre-NEFA PEG-treated cows. Similar to our findings on the rate of insemination, the pre-NEFA by treatment interaction remained present in the models with or without clinical disease, showing that PEG decreased the hazard of culling in high pre-NEFA cows independent of a reduction in the occurrence of clinical diseases. Undoubtedly, a major reason for culling is reproductive failure (Kossaibati and Esslemont, 1997; LeBlanc et al., 2002) and we found that PEG treatment improved fertility in high pre-NEFA cows (i.e., higher rate of first insemination and higher rate of pregnancy in either CM or UD cows). Thus, the data suggest that the reduction in hazard of culling in PEG-treated cows may be a combination of a reduction in $\mathrm{CM}$ and improved fertility. Stratified analyses showed that, in multiparous cows that subsequently recorded CM, PEG treatment tended to result in a lower hazard of culling. Moreover, our data suggest that CM impaired fertility, particularly in multiparous cows. It has been shown that multiparous cows respond more severely to the same intramammary challenge (Vangroenweghe et al., 2004); thus, the suggested immune modulation due to PEG, decreasing the severity of CM (Powell et al., 2018), would be more beneficial for multiparous cows. The finding that PEG treatment decreased the hazard of culling is particularly important, since it is one of the main factors associated with the negative economic consequences of disease in dairy farming (Hogeveen et al., 2017). 
We allocated treatment based on the national ear tag number. If there would be periodicity in the allocation of the national ears tags at birth, bias would have been introduced. However, these consecutively numbered tags are allocated to the calves in order of birth, which makes bias in relation to future performance unlikely. Moreover, the balance between treatment groups suggests that randomization was successful. A second potential limitation is the fact that research assistants who applied the treatment were aware of treatment status, and this could bias their objectivity when assessing BCS, metritis, and endometritis. However, all cow observations were linked to the cow ID, an ear tag number completely different and unrelated to the national ear tag number. Moreover, all farm personnel and veterinarians that assessed the outcomes of interest in this study (estrus detection, insemination, pregnancy diagnoses, and culling decisions) and laboratory personnel that determined prepartum NEFA concentrations were blinded with regard to treatment status.

We consider that these results contribute to a more efficient use of PEG treatment because our data suggest that it may be used specifically in cows at risk for immune imbalances related to metabolic disturbances, as present in high pre-NEFA cows. In this study we found a relatively high prevalence $(61 \%)$ of animals with increased pre-NEFA values, being apparently higher in primiparous cows $(74 \%)$ than in multiparous cows $(54 \%)$. This is consistent with previous reports from our research group in pasture-based herds (Meikle et al., 2004; Adrien et al., 2012). Despite major advances in diagnosis and management of NEB (Overton et al., 2017), excessive NEB still affects an important number of modern dairy cows (Ospina et al., 2013; Macrae et al., 2019). The challenge is to identify high pre-NEFA cows easily and fast, as there is currently no cow-side test available (Overton et al., 2017). The emerging areas of big data, metabolomics, and the use of automatic sensors to measure metabolic health (Overton et al., 2017) are promising technologies to identify cows that would benefit most from treatment with PEG. No association of pre-BCS or its interaction with treatment was found with any of the outcomes considered. There is an association between prepartum BCS and prepartum NEFA concentration (Roche et al., 2015), which could potentially introduce multicollinearity in the statistical models. However, since modeling was done using a manual forward selection procedure, variables such as pre-BCS and pre-NEFA were offered to the models one by one, preventing potential multicollinearity and overlapping effects. It has been shown that cows that lost body condition before calving had increased peripartum NEFA concentrations (Barletta et al., 2017; Sheehy et al., 2017). We only assessed BCS once, immediately before treatment. In future studies, BCS dynamics, which may now be performed using commercially available automated sensors (Mullins et al., 2019), would be more relevant than a one-time assessment and could give further insights in the use of PEG.

Our results suggest an important impact of PEG treatment on cow health (Barca et al., 2021b), fertility, and longevity (this study). Further economic analyses will be necessary to evaluate the cost benefit ratio of PEG treatment.

\section{CONCLUSIONS}

This study shows that the effect of PEG treatment on fertility and culling interacts with pre-NEFA. In low pre-NEFA cows, no treatment effect was detected. In high pre-NEFA cows, PEG treatment increased the rate of first insemination, counteracted the negative association of early-lactation CM and UD with the rate of pregnancy and decreased the hazard of culling.

\section{ACKNOWLEDGMENTS}

The cooperation of farmers and farm personnel is gratefully acknowledged. Funding was provided by Elanco Animal Health (Greenfield, IN) and the University of the Republic, Uruguay. The authors have not stated any conflicts of interest.

\section{REFERENCES}

Adrien, M. L., D. A. Mattiauda, V. Artegoitía, M. Carriquiry, G. Motta, O. Bentancur, and A. Meikle. 2012. Nutritional regulation of body condition score at the initiation of the transition period in primiparous and multiparous dairy cows under grazing conditions: Milk production, resumption of post-partum ovarian cyclicity and metabolic parameters. Animal 6:292-299. https://doi.org/ 10.1017/S175173111100142X.

Bar, D., Y. T. Grohn, G. Bennett, R. N. Gonzalez, J. A. Hertl, H. F. Schulte, L. Tauer, F. L. Welcome, and Y. H. Schukken. 2008. Effects of repeated episodes of generic clinical mastitis on mortality and culling in dairy cows. J. Dairy Sci. 91:2196-2204. https://doi .org/10.3168/jds.2007-0460.

Barca, J. 2021. Barca et al., 2021. Supplemental Tables. http://dx.doi .org/DOI:10.17632/ftkm7775kn.3.

Barca, J., A. Meikle, M. Bouman, G. Gnemmi, R. Ruiz, and Y. H. Schukken. 2021b. Effect of pegbovigrastim on clinical mastitis and uterine disease during a full lactation in grazing dairy cows. PLoS One 16:e0252418. https://doi.org/10.1371/journal.pone.0252418.

Barca, J., Y. H. Schukken, and A. Meikle. 2021a. Increase in white blood cell counts by pegbovigrastim in primiparous and multiparous grazing dairy cows and the interaction with prepartum body condition score and non-esterified fatty acids concentration. PLoS One 16:e0245149. https://doi.org/10.1371/journal.pone.0245149.

Barletta, R. V., M. Maturana Filho, P. D. Carvalho, T. A. Del Valle, A. S. Netto, F. P. Rennó, R. D. Mingoti, J. R. Gandra, G. B. Mourão, P. M. Fricke, R. Sartori, E. H. Madureira, and M. C. Wiltbank. 2017. Association of changes among body condition score during the transition period with NEFA and BHBA concentrations, milk 
production, fertility, and health of Holstein cows. Theriogenology 104:30-36. https://doi.org/10.1016/j.theriogenology.2017.07.030.

Bewley, J., M. Boehlje, A. W. Gray, H. Hogeveen, S. Kenyon, S. Eicher, and M. Schutz. 2010. Stochastic simulation using @Risk for dairy business investment decisions. Agr. Financ. Rev. 70:97-125. https://doi.org/10.1108/00021461011042666.

Bradford, B. J., K. Yuan, J. K. Farney, L. K. Mamedova, and A. J. Carpenter. 2015. Invited review: Inflammation during the transition to lactation: New adventures with an old flame. J. Dairy Sci. 98:6631-6650. https://doi.org/10.3168/jds.2015-9683.

Burfeind, O., V. S. Suthar, and W. Heuwieser. 2012. Effect of heat stress on body temperature in healthy early postpartum dairy cows. Theriogenology 78:2031-2038. https://doi.org/10.1016/j theriogenology.2012.07.024.

Canning, P., R. Hassfurther, T. TerHune, K. Rogers, S. Abbott, and D. Kolb. 2017. Efficacy and clinical safety of pegbovigrastim for preventing naturally occurring clinical mastitis in periparturient primiparous and multiparous cows on US commercial dairies. J. Dairy Sci. 100:6504-6515. https://doi.org/10.3168/jds.2017-12583.

Caraviello, D. Z., K. A. Weigel, M. Craven, D. Gianola, N. B. Cook, K. V. Nordlund, P. M. Fricke, and M. C. Wiltbank. 2006. Analysis of reproductive performance of lactating cows on large dairy farms using machine learning algorithms. J. Dairy Sci. 89:4703-4722. https://doi.org/10.3168/jds.S0022-0302(06)72521-8.

Carvalho, M. R., F. Peñagaricano, J. E. P. Santos, T. J. DeVries, B. W. McBride, and E. S. Ribeiro. 2019. Long-term effects of postpartum clinical disease on milk production, reproduction, and culling of dairy cows. J. Dairy Sci. 102:11701-11717. https://doi .org/10.3168/jds.2019-17025.

Cox, D. R. 1972. Regression models and life-tables. J. R. Stat. Soc. Series B Stat. Methodol. 34:187-202.

Dolecheck, K. A., A. García-Guerra, and L. E. Moraes. 2019. Quantifying the effects of mastitis on the reproductive performance of dairy cows: A meta-analysis. J. Dairy Sci. 102:8454-8477. https:// doi.org/10.3168/jds.2018-15127.

Drackley, J. K. 1999. Biology of dairy cows during the transition period: The final frontier. J. Dairy Sci. 82:2259-2273. https://doi .org/10.3168/jds.S0022-0302(99)75474-3.

Ferguson, J. D., D. T. Galligan, and N. Thomsen. 1994. Principal descriptors of body condition score in Holstein cows. J. Dairy Sci. 77:2695-2703. https://doi.org/10.3168/jds.S0022-0302(94)77212 -X.

Fourichon, C., H. Seegers, and X. Malher. 2000. Effect of disease on reproduction in the dairy cow: A meta-analysis. Theriogenology 53:1729-1759. https://doi.org/10.1016/S0093-691X(00)00311-3.

Freick, M., M. Zenker, O. Passarge, and J. Weber. 2018. Reducing the incidence of acute puerperal metritis in primiparous cows by application of pegbovigrastim in a Holstein dairy herd. Vet. Med. 63:151-160. https://doi.org/10.17221/2/2018-VETMED.

Galvão, K. N., M. J. B. F. Flaminio, S. B. Brittin, R. Sper, M. Fraga, L. Caixeta, A. Ricci, C. L. Guard, W. R. Butler, and R. O. Gilbert. 2010. Association between uterine disease and indicators of neutrophil and systemic energy status in lactating Holstein cows. J. Dairy Sci. 93:2926-2937. https://doi.org/10.3168/jds.2009-2551.

Gilbert, R. O., and N. R. Santos. 2016. Dynamics of postpartum endometrial cytology and bacteriology and their relationship to fertility in dairy cows. Theriogenology 85:1367-1374. https://doi.org/ 10.1016/j.theriogenology.2015.10.045.

Gross, J. J., and R. M. Bruckmaier. 2019. Invited review: Metabolic challenges and adaptation during different functional stages of the mammary gland in dairy cows: Perspectives for sustainable milk production. J. Dairy Sci. 102:2828-2843. https://doi.org/10.3168/ jds.2018-15713.

Grummer, R. R. 1995. Impact of changes in organic nutrient metabolism on feeding the transition dairy cow. J. Anim. Sci. 73:28202833. https://doi.org/10.2527/1995.7392820x.

Hachenberg, S., C. Weinkauf, S. Hiss, and H. Sauerwein. 2007. Evaluation of classification modes potentially suitable to identify metabolic stress in healthy dairy cows during the peripartal period. J. Anim. Sci. 85:1923-1932. https://doi.org/10.2527/jas.2006-480.
Hertl, J. A., Y. H. Schukken, L. W. Tauer, F. L. Welcome, and Y. T. Gröhn. 2018. Does clinical mastitis in the first 100 days of lactation 1 predict increased mastitis occurrence and shorter herd life in dairy cows? J. Dairy Sci. 101:2309-2323. https://doi.org/10.3168/ jds.2017-12615.

Hogeveen, H., F. J. S. van Soest, and M. van der Voort. 2017. The economic consequences of production diseases in dairy farming. Pages 1165-1175 in Large Dairy Herd Management. 3rd ed. D. K. Beede, ed. American Dairy Science Association.

Ingvartsen, K. L., and K. M. Moyes. 2015. Factors contributing to immunosuppression in the dairy cow during the periparturient period. Jpn. J. Vet. Res. 63(Supplement 1):S15-S24.

Kimura, K., J. P. Goff, P. Canning, C. Wang, and J. A. Roth. 2014. Effect of recombinant bovine granulocyte colony-stimulating factor covalently bound to polyethylene glycol injection on neutrophil number and function in periparturient dairy cows. J. Dairy Sci. 97:4842-4851. https://doi.org/10.3168/jds.2013-7242.

Kossaibati, M. A., and R. J. Esslemont. 1997. The costs of production diseases in dairy herds in England. Vet. J. 154:41-51. https://doi .org/10.1016/S1090-0233(05)80007-3.

Lacetera, N., D. Scalia, U. Bernabucci, B. Ronchi, D. Pirazzi, and A. Nardone. 2005. Lymphocyte functions in overconditioned cows around parturition. J. Dairy Sci. 88:2010-2016. https://doi.org/10 .3168/jds.S0022-0302(05)72877-0.

LeBlanc, S. J. 2020. Review: Relationships between metabolism and neutrophil function in dairy cows in the peripartum period. Animal 14(S1):s44-s54. https://doi.org/10.1017/S1751731119003227.

LeBlanc, S. J., T. F. Duffield, K. E. Leslie, K. G. Bateman, G. P. Keefe, J. S. Walton, and W. H. Johnson. 2002. Defining and diagnosing postpartum clinical endometritis and its impact on reproductive performance in dairy cows. J. Dairy Sci. 85:2223-2236. https://doi.org/10.3168/jds.S0022-0302(02)74302-6.

LeBlanc, S. J., T. H. Herdt, W. M. Seymour, T. F. Duffield, and K. E. Leslie. 2004. Peripartum serum vitamin E, retinol, and beta-carotene in dairy cattle and their associations with disease. J. Dairy Sci. 87:609-619. https://doi.org/10.3168/jds.S0022-0302(04)73203 -8 .

Lüttgenau, J., S. Purschke, G. Tsousis, R. M. Bruckmaier, and H. Bollwein. 2016. Body condition loss and increased serum levels of nonesterified fatty acids enhance progesterone levels at estrus and reduce estrous activity and insemination rates in postpartum dairy cows. Theriogenology 85:656-663. https://doi.org/10.1016/j theriogenology.2015.10.003.

Macrae, A. I., E. Burrough, J. Forrest, A. Corbishley, G. Russell, and D. J. Shaw. 2019. Prevalence of excessive negative energy balance in commercial United Kingdom dairy herds. Vet. J. 248:51-57. https://doi.org/10.1016/j.tvjl.2019.04.001.

McDougall, S., S. J. LeBlanc, and A. Heiser. 2017. Effect of prepartum energy balance on neutrophil function following pegbovigrastim treatment in periparturient cows. J. Dairy Sci. 100:7478-7492. https://doi.org/10.3168/jds.2017-12786.

Meikle, A., M. Kulcsar, Y. Chilliard, H. Febel, C. Delavaud, D. Cavestany, and P. Chilibroste. 2004. Effects of parity and body condition at parturition on endocrine and reproductive parameters of the cow. Reproduction 127:727-737. https://doi.org/10.1530/rep .1 .00080 .

Melendez, P., M. P. Marin, J. Robles, C. Rios, M. Duchens, and L. Archbald. 2009. Relationship between serum nonesterified fatty acids at calving and the incidence of periparturient diseases in Holstein dairy cows. Theriogenology 72:826-833. https://doi.org/ 10.1016/j.theriogenology.2009.06.001.

Mullins, I. L., C. M. Truman, M. R. Campler, J. M. Bewley, and J. H. C. Costa. 2019. Validation of a commercial automated body condition scoring system on a commercial dairy farm. Animals (Basel) 9:287. https://doi.org/10.3390/ani9060287.

Ospina, P. A., J. A. McArt, T. R. Overton, T. Stokol, and D. V. Nydam. 2013. Using nonesterified fatty acids and $\beta$-hydroxybutyrate concentrations during the transition period for herd-level monitoring of increased risk of disease and decreased reproductive and 
milking performance. Vet. Clin. North Am. Food Anim. Pract. 29:387-412. https://doi.org/10.1016/j.cvfa.2013.04.003.

Overton, T. R., J. A. A. McArt, and D. V. Nydam. 2017. A 100year review: Metabolic health indicators and management of dairy cattle. J. Dairy Sci. 100:10398-10417. https://doi.org/10.3168/jds .2017-13054.

Pinzón-Sánchez, C., and P. L. Ruegg. 2011. Risk factors associated with short-term post-treatment outcomes of clinical mastitis. J. Dairy Sci. 94:3397-3410. https://doi.org/10.3168/jds.2010-3925.

Powell, E. J., T. A. Reinhardt, E. Casas, and J. D. Lippolis. 2018. The effect of pegylated granulocyte colony-stimulating factor treatment prior to experimental mastitis in lactating Holsteins. J. Dairy Sci. 101:8182-8193. https://doi.org/10.3168/jds.2018-14550.

Ribeiro, E. S., G. Gomes, L. F. Greco, R. L. A. Cerri, A. Vieira-Neto, P. L. J. Monteiro Jr., F. S. Lima, R. S. Bisinotto, W. W. Thatcher, and J. E. P. Santos. 2016. Carryover effect of postpartum inflammatory diseases on developmental biology and fertility in lactating dairy cows. J. Dairy Sci. 99:2201-2220. https://doi.org/10.3168/ jds.2015-10337.

Roche, J. R., N. C. Friggens, J. K. Kay, M. W. Fisher, K. J. Stafford, and D. P. Berry. 2009. Invited review: body condition score and its association with dairy cow productivity, health, and welfare. J. Dairy Sci. 92:5769-5801. https://doi.org/10.3168/jds.2009-2431.

Roche, J. R., S. Meier, A. Heiser, M. D. Mitchell, C. G. Walker, M. A. Crookenden, M. V. Riboni, J. J. Loor, and J. K. Kay. 2015. Effects of precalving body condition score and prepartum feeding level on production, reproduction, and health parameters in pasture-based transition dairy cows. J. Dairy Sci. 98:7164-7182. https://doi.org/ 10.3168/jds.2014-9269.

Ruiz, R., L. O. Tedeschi, and A. Sepulveda. 2017. Investigation of the effect of pegbovigrastim on some periparturient immune disorders and performance in Mexican dairy herds. J. Dairy Sci. 100:33053317. https://doi.org/10.3168/jds.2016-12003.

Sargeant, J. M., A. M. O'Connor, I. A. Gardner, J. S. Dickson, M. E. Torrence, I. R. Dohoo, S. L. Lefebvre, P. S. Morley, A. Ramirez, and K. Snedeker. 2010. The REFLECT statement: Reporting guidelines for randomized controlled trials in livestock and food safety: Explanation and elaboration. J. Food Prot. 73:579-603. https://doi.org/10.4315/0362-028X-73.3.579.

Schukken, Y. H., J. Gunther, J. Fitzpatrick, M. C. Fontaine, L. Goetze, O. Holst, J. Leigh, W. Petzl, H. J. Schuberth, A. Sipka, D. G. Smith, R. Quesnell, J. Watts, R. Yancey, H. Zerbe, A. Gurjar, R. N. Zadoks, and H. M. Seyfert. 2011. Host-response patterns of intramammary infections in dairy cows. Vet. Immunol. Immunopathol. 144:270-289. https://doi.org/10.1016/j.vetimm.2011.08 .022 .
Sheehy, M. R., A. G. Fahey, S. P. Aungier, F. Carter, M. A. Crowe, and F. J. Mulligan. 2017. A comparison of serum metabolic and production profiles of dairy cows that maintained or lost body condition 15 days before calving. J. Dairy Sci. 100:536-547. https: //doi.org/10.3168/jds.2016-11206.

Sheldon, I. M., G. S. Lewis, S. LeBlanc, and R. O. Gilbert. 2006 Defining postpartum uterine disease in cattle. Theriogenology 65:1516-1530. https://doi.org/10.1016/j.theriogenology.2005.08 .021 .

Toni, F., L. Vincenti, A. Ricci, and Y. H. Schukken. 2015. Postpartum uterine diseases and their impacts on conception and days open in dairy herds in Italy. Theriogenology 84:1206-1214. https://doi .org/10.1016/j.theriogenology.2015.06.022.

Trevisi, E., and A. Minuti. 2018. Assessment of the innate immune response in the periparturient cow. Res. Vet. Sci. 116:47-54. https: //doi.org/10.1016/j.rvsc.2017.12.001.

Van Schyndel, S. J., J. Carrier, O. Bogado Pascottini, and S. J. LeBlanc. 2018. The effect of pegbovigrastim on circulating neutrophil count in dairy cattle: A randomized controlled trial. PLoS One 13:e0198701. https://doi.org/10.1371/journal.pone.0198701.

Van Schyndel, S. J., J. Dubuc, O. B. Pascottini, J. Carrier, D. F. Kelton, T. F. Duffield, and S. J. LeBlanc. 2021. The effect of pegbovigrastim on early-lactation disease, production, and reproduction in dairy cows. J. Dairy Sci. 104:10100-10110. https://doi.org/10 .3168/jds.2021-20266.

Vangroenweghe, F., L. Duchateau, and C. Burvenich. 2004. Moderate inflammatory response during experimental Escherichia coli mastitis in primiparous cows. J. Dairy Sci. 87:886-895. https://doi.org/ 10.3168/jds.S0022-0302(04)73233-6.

Zinicola, M., H. Korzec, A. G. V. Teixeira, E. K. Ganda, L. Bringhenti, A. C. C. H. Tomazi, R. O. Gilbert, and R. C. Bicalho. 2018. Effects of pegbovigrastim administration on periparturient diseases, milk production, and reproductive performance of Holstein cows. J. Dairy Sci. 101:11199-11217. https://doi.org/10.3168/jds .2018-14869.

\section{ORCIDS}

Joaquín Barca @ https://orcid.org/0000-0002-5171-3284

Ana Meikle @ https://orcid.org/0000-0002-0847-8629

Mette Bouman () https://orcid.org/0000-0002-3264-2409

Ynte H. Schukken ® https://orcid.org/0000-0002-8250-4194 